\title{
Entre o minério e a pedra: a poesia de Márcio Almeida e de Carlos Ávila
}

Edgard Pereira Universidade Federal de Minas Gerais

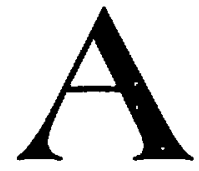

poesia elaborada pelos poetas surgidos nos anos oitenta é caudatária de duas tendências antagônicas: de um laclo, seguidores fiéis do concretismo, numa pulsaçĩo epigônica: de outro, os praticantes de uma escrita poética discursiva, com raízes no surrealismo europeu ou na lírica beat americana. A enumeração de nomes é complexa e demorada, correndo o risco de se revelar parcial, em função dos diversificados modos de estréia e permanência. Carlos Ávila, Régis Bonvicino, Ronald Polito, Waly Salomão, Arnaldo Antunes, entre outros, compõem o grupo de formação neo-concreta. No extremo oposto (nem tão oposto assim, visto que muitos de cá transitam também do lado de lá e vice-versa) Márcio Almeida, Osvaldo André de Melo, Yacyr Anderson, Paulo Henriques Brito, Antônio Cícero, Armando Freitas Filho, Geraldo Reis, Adão Ventura, Adélia Prado, João Evangelista Rodrigues, entre outros, alinham-se na vertente da poética discursiva, com acento numa subjetiviclade às vezes rebelde e excessiva, na seqüência de contribuição efetuada por Roberto Piva, Cláudio Willer, Hilda Hilst na década de sessenta. Estes últimos, embora menos agraciados pela crítica, realizaram uma obra notável na contramão do que sc convencionou clenominar vanguarda.

Voltando aos nomes, os mineiros, como se vê, constituem maioria num elenco sumário; Minas é um celeiro de grandes poetas, embora votados ao esquecimento. Mostra clesse olvido: a revista portuguesa Relâmpago dedica seu número sete à atual poesia 
brasileira, contemplando, entretanto, apenas poetas cariocas. Outro quadro atípico: acúmulo de obras premiadas e inéditas. Quase todos continuam ignorados, dizer esquecimento soa a eufemismo. Cadê as políticas culturais?

A questão é complexa e fica para outra oportunidade. Desde que surgiu o concretismo, persistir na elaboração de uma poesia com acento na subjetividade algumas vezes delirante era uma proposta ousada e radical. Paralela ao oportuno contributo para superar uma tradição marcadamente formalista e altissonante, contaminada por excessos sentimentais, vinculada ao verso rimado e metrificado, na esteira dos parâmetros parnasianos nem sempre bem assimilados, a prática da poesia concreta estabeleceu objetivos claros de pesquisa e contenção, além de criar na própria linguagem sua referência e seu objeto. Declaram encerrado o ciclo do verso tradicional. Suas propostas iniciais, reagindo contra o sistema poético vigente, trouxeram inegável sopro renovador à poesia brasileira nas décadas de cinqüenta a setenta, quando seus processos passam a se tornar repetitivos e estéreis, solidificando-se num campo de associações por demais previsiveis. Os desdobramentos dessa saturação (para não dizer estagnação em trilhas propícias às piruetas visuais) podem ser percebidos em alguns movimentos que se sucederam: poesia práxis, poesia marginal, poema-processo, poesia sonora.

...muitos dos procedimentos estéticos inventados na fase heróica dos movimentos de vanguarda e levados às últimas consequiências pelos movimentos posteriores, como as técnicas do simultaneísmo, a fragmentaçào, a montagem e a colagem, dentre outras, converteramse em práticas rotinizadas - porque esvaziadas de seu efeito transgressor - dentro do que passou a ser designado de pósmodernidade.'

Nos dias que passam, não se olvide a obsessão de certas tendências experimentais (como se toda poesia não devesse ser por natureza experimental) insistindo na urgência de a palavra poética

' MACIEL, 1999. p. 44. 
associar-se a códigos não-verbais. No fogo cruzado da arena cultural, as coisas se passam às vezes com pressões surdas, quando não por meio de patrulhas orquestradas por grupos solidários. Talvez seja oportuno mencionar a riqueza da diversidade, aincla mais agora em que os limites do literário se revelam extremamente esbatidos e contaminados por outros campos estéticos, como aliás tem feito a crítica mais esclarecida:

O diálogo de poetas contemporâneos com as tecnologias de ponta e outros campos artísticos, é bom marcar, nào está associado à desvalorizaçào ou ao desaparecimento da palavra escrita e do poema inteiramente verbal. Se muitos poetas, mais intermediáticos, conseguem conjugar as duas coisas, outros já optaram por uma retomada mais efetiva da palavra escrita e até mesmo de uma certa narratividade, compreendida como forma poética alternativa."

A questão é complexa e fica para outra oportunidade. Detenhome por ora em dois poetas, em cuja poesia reverberam alguns impasses decisivos da poesia brasileira contemporânea.

Márcio Almeida, com extensa produção, em sua maioria inédita ou editada de forma precária ou descuidada, apesar de ter conquistado mais de sessenta prêmios literários (entre eles, o Emílio Moura, de 1971, e o Cidade de Belo Horizonte, de 2000), é um dos nomes representativos da atual poesia brasileira. Criador dos movimentos Vix e Frente (Oliveira/MG), imprime em sua escrita uma forte consciência social, alicerçada numa requintada elaboraçāo da linguagem oral, atravessada por um repertório léxico colhido no cotidiano, a que não sĩo estranhas algumas tonalidades arcaicas.

O povo é o homem que berra sua fome, sonho e promessa; é o boi mais solto na terra carreando dor e homessa."

2 MACIEL, 1999. p. 47.

' BARRETO et alii, 1977. p. 104. 
Consciente de que a poesia dialoga com a história e de que a palavra é portadora de um "brilho a seco" de diamante, denuncia a ação predatória do homem contra a natureza, mencionando o desaparecimento das montanhas e suas conseqüências nefastas - "a herança que da perda cobra o dano/ do homem que respira e vai morrendo". "Em seu trabalho poético, empreende uma redescoberta poética da terra, na procura de perceber a intima integração entre os elementos naturais e o homem, realçando as raízes históricas e geológicas da mineiridade:

a pedra flora dos ritos em com fins dentes abruptos e em mim nério esse néctar resumo telúrico do tempo.

Numa sintaxe cabralina, o entrelaçamento do destino humano e o do boi aponta para o vertiginoso desgaste dos recursos naturais. A paisagem nunca é decorativa ou neutra nesta poesia, mas o resultado da ação do homem e dos animais, dos insetos e clos pássaros, das plantas e das águas. Daí o verso "mim nério esse néctar", acentuando a interioridade do processo, minério em mim: a tentativa de enraizar a substância interior e seus desdobramentos não estariam apontando o regresso ao ventre materno, criação de um espaço protetor e protegiclo, disposição de habitar a interioridade da matéria? O processo poético consiste em explorar a mais valia das palavras, tirar proveito de sua plurissignificação, realçando as relações antitéticas ou paronomásicas, pondo a nu as associações entre o eruclito e o popular:

lá vai o boi para o pasto que o matadouro não tarda, o boi no homem é mais vasto vestido de verde e de carda."

' BARRETO et alii, 1977. p. 119.

' BARRETO et alii, 1977. p. 112.

'BARRETO et alii, 1977. p. 94. 
Entre os últimos trabalhos de Márcio de Almeida, observamse poemas permeados de associações palavra/imagem, na seqüência de um labor iniciado no final da década de setenta, quando fazia circular em camisctas coloridas versos breves (como: neste sol vocês verāo), tornando realidade uma tendência da arte atual em se desvencilhar cla noçio de aura e se tornar um objeto de consumo, segundo a lição de Benjamin. Essas e outras questões teóricas são revisitadas, ao lado de experiências de poesia visual, em apêndice à coletânea Lâpis impuro, vindas a lume $\mathrm{cm}$ recente antologia.' Desconstruindo modos poéticos tradicionais, insere na página o desenhar-ver-ler do signo, encarecendo uma nova aprendizagem da sensibilidade e da leitura.

Outro pocta contemporâneo, originário de Minas e com repercussão nacional, é Carlos Ávila. Ao contrário de Márcio Almeida, este é um pocta extremamente cuidacloso na edição de seus livros. No seu caso, o fato de possuir um nome emblemático para a poesia brasileira, tendo inspirado no berço um poema de Carlos Drummond de Andrade (além de exibir uma ascendência literária ilustre), acaba se tornando motivo de gestos inventivos rebeldes, seja ao rasurar num poema o parentesco ( $\mathrm{sem} \mathrm{som} /$ sombra/sobrenome), seja ao inscrever sua indiferença "contra a chamada literatura brasileira/ uma grande piada sem graça”. Artesão refinado, Ávila imprime em seu trabalho poético uma reelaboração irônica dos clichês, uma interlocuçào com uma dezená de poctas críticos e uma apurada concentração lírica, a clespeito de toda uma filiação aos parâmetros concretistas. A esse aspecto, o poema "Noite" é uma acertada referência, na medida en que o desenlace engloba as articulações anteriores de estrelas/janelas que se apagam para concluir: "a noitc cai/ (como um sussurro)/ dura de doer".

A poesia concreta de Carlos Ávila consegue, como bem percebeu José Paulo Paes, "fugir às armadilhas do epigonismo", em grande parte através de alguns modos poéticos que se contrapõem

:TORRES (Org), 2000. 
frontalmente a diretrizes orgânicas do "Plano piloto". Entre elas, a retomada da subjetividade, ainda que desprovida de confessionalismo e direcionada para a construção de uma identidacle poética (o percurso de eu a orfeu), bem como alguns tênues traços de narratividade (como se pode observar em "Um lance", "Baudelaire sob o sol", "Neighbours", "Narcissus poeticus"). Não seriam esses torneios narrativos outros indices da aspereza do último livro, acentuada já no título - Ásperos? Talvez fosse bizantino realçar outro aspecto que faz dele um poeta para poetas, a se levar em conta as alusōes a nomes dos mais variados quilates (de Verlaine a Emily, Baudelaire, Kilkerry, Drummond, Torquato Neto, Rimbaud, Mallarmé, Apollinaire, Sá-Carneiro, Ronaldo Bastos, entre outros), configurando a poética da citação praticada pelos pós-modernos.

Outro dado ligado à poética marginal, nas dobras do "retorno amistoso do autor ao texto" de que fala Barthes a propósito da escrita dos anos oitenta, vem a ser a ênfase no autoral, através de traços personalizados (foto, assinatura), revitalizando traços dos astros pop. A assinatura se dá numa caligrafia, uma grafia da cal, o que remete a Lacan, falando dos mestres japoneses: a caligrafia é o ponto onde a letra se faz litoral, mas não sabemos de que ponto ela arranca, nem o lugar em que ela se detém. E não seria também a caligrafia do nome próprio na página em branco uma poderosa metáfora narcísica?

$A$ intertextualidade com Rimbaud destaca a vidência como forma de penetrar no espaço desconhecido, atualizando a idéia de poeta como ladrão de fogo, na raiz dessa auto inscrição num veio marginal de produção poética: "sou o farelo do pão/ ladrão de palavras/ no vão/ do ão" ("Rima pobre"). A originalidade de sua vo\%. poética resulta de se mostrar aberta a "direção múltipla de leituras", coino sugere um dos pontos altos da coletânea:

voltar a cabeça, a página

perder o texto em vida

em dias 


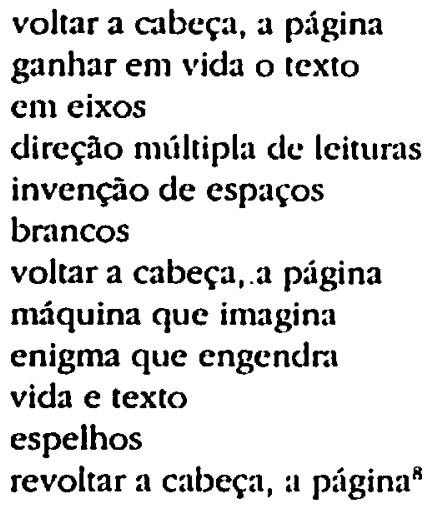

A linguagem passou de instrumento a objeto de poesia $\mathrm{cm}$ meados do séc. XX. Depois de visitarem a cidade, na companhia de Baudelaire, os poetas acercaram-se da linguagem para tentar descrevê-la e conhecer os seus limites - "ganhar em vida o texto". O poema embaralha os conceitos de escrever e viver, ao apelar para o antitético (e além de camoniano, drummondiano) jogo de perder/ ganhar, construindo um jogo de reflexos apto a fazer circular eixos fundamentais da produçào poética: espaços brancos, máquina (do mundo), (claro) enigina, página, textos, a que não faltam as idéias de risco biblico de voltar/revoltar a cabeça, recomeçando sempre o nunca terminado. À parte as idiossincrasias e audácias, estamos diante de um imenso pocta.

A esta altura, alguém, talvez já cansado de alguma paráfrase pobre, estará indagando: por que aproximar Márcio Almeicla e Carlos Ávila, como se o fato de ambos serem poetas pouco justificasse. Se há um motivo outro que os interseccione, este é o da terra, sob a forma de minério em Márcio Almeida ("mim nério esse néctar"), denunciando a devastaçào da natureza; sob a égicle de pedra na poesia de Carlos Ávila, percebida por vários glosadores ("pedra grossa e/ lavra fina", "substrato sólido, superfície transparente: pedra viva").

" ÁVILA, 1999. p.131. 


\section{Referências Bibliográficas}

ÁVILA, Carlos. Bissexto sentido. São Paulo: Perspectiva, 1999.

BARRETO, Antônio et alii. Antologia poética 2. Belo Horizonte: Interlivros, 1977.

MACIEL, Maria Esther. Vôo transıerso-poesia, modernidade e fim do século $X X$. Rio de Janeiro: Sette Letras, 1999.

TORRES, Wagner. (Org). Cantária. Belo Horizonte: Plurarts, 2000.

\section{Resumo}

Algumas reflexỏes sobre a poesin brasileira contemporânea, clestracanclo a produção de dois jovens poetas, Márcio Almeida e Carlos Ávila.

\section{Résumé}

Quelques réflexions sur la poésie brésilienne contemporaine et sur deux poètes récentes, Márcio Almeida e Carlos Kvila. 